\title{
Evaluation of Volcanic Ash Concentration Effect on Mechanical Properties of Poly(Vinyl Chloride) Composites
}

\author{
M.Ö. BORA* \\ Kocaeli University, School of Civil Aviation, 41285 Izmit, Turkey
}

\begin{abstract}
Various concentrations of inorganic particles of volcanic ashes (VA) were added using twin screw extruder and the injection molding machines to the poly(vinyl chloride) (PVC) to fabricate PVC/VA composites. The effect of volcanic ash particles weight content $(0,5,10,15,20$, and 25 wt.\%) on the mechanical properties of PVC/VA composites was investigated by tensile and flexural tests. Tensile and flexural properties of composite samples were determined under three different temperatures $\left(-10{ }^{\circ} \mathrm{C}, 20{ }^{\circ} \mathrm{C}\right.$ and $\left.50{ }^{\circ} \mathrm{C}\right)$ by using Shimadzu AG-X test machine, having a load cell of $10 \mathrm{kN}$ and equipped with the thermostatic chamber with controlled temperature environment. As a result, mechanical properties of PVC/VA composites showed that VA can be used as a filler material in PVC composites. Results of both, the tensile and the flexural tests showed that at $-10{ }^{\circ} \mathrm{C}$ and at $20{ }^{\circ} \mathrm{C}$, flexural and tensile strength values of $25 \mathrm{wt} . \% \mathrm{PVC} / \mathrm{VA}$ composites have decreased by nearly $15 \%$, compared to value of pure PVC. Even though VA particles decrease the flexural and tensile strength of PVC, VA can be used as a filler material in PVC matrix. Morphologies of the fracture surfaces and the dispersion of VA particles were observed by using scanning electron microscopy (SEM).
\end{abstract}

DOI: $10.12693 /$ APhysPolA.127.1004

PACS: 81.05.Qk

\section{Introduction}

The study of the mechanical properties of polymer composites have made it desirable to choose these materials over traditional materials for numerous types of applications, such as binder constituents in explosives, loadbearing components, and jet engine modules. As the uses of polymer composites increase, the understanding of the mechanical behavior of these materials becomes vital for creating innovative and economical designs for various components [1]. Poly(vinyl chloride) (PVC) is a commodity thermoplastic that has been widely used in many industrial applications, such as pipes, electric wires, window profiles, siding, etc. Its versatility for accepting numerous additives, extraordinary stability to weathering, and competitive price, are the reasons for the success of PVC. Recently, rigid particle fillers have been extensively used in creating polymer composites with good modulus, strength and rigidity. Therefore, researchers are constantly investigating ways to produce the polymer composites with balanced mechanical properties at a reasonable production cost. One of the common ways is to incorporate low-cost fillers into the PVC matrix [2]. Volcanic ash (VA), which is deposited at the surface during volcanic activity, is readily accessible and has the advantage that it can be economically mined, with enormous benefits of low cost and limited negative environmental impact, compared with traditional open pit quarry-type clay mining. VA is known as the mesoporous material, which usually has high specific surface area, significant

*e-mail: ozgur_bora@yahoo.com porosity, and an appropriate pore structure, which enhances its ability to control the humidity in the environment [3]. Literature surveys revealed that numerous research efforts had been made to improve the mechanical properties and to fabricate low-cost inorganic fillers, based on silica [4], calcium carbonate [5], montmorillonite [6], clay [7] and titania [8] PVC composites. On the other hand, there are no research attempts to study mechanical properties of volcanic ash-reinforced PVC matrix. The aim of this work is to study the influence of concentration of VA particles in the PVC matrix on the tensile and flexural properties at three different temperatures $\left(-10{ }^{\circ} \mathrm{C}, 20{ }^{\circ} \mathrm{C}\right.$ and $\left.50{ }^{\circ} \mathrm{C}\right)$. The results obtained for PVC composites with different VA concentrations were correlated with the function of flexural strength-modulus and tensile strength-modulus. Beside this, the morphology of fracture surfaces of the PVC composites was observed by a scanning electron microscope (SEM).

\section{Materials and method}

\subsection{Materials}

PVC (D100 TE) used as the matrix resin for the micro-compounding and injection molding was provided by Ankara Granül Co. The D100 TE is of the unfilled grade for extrusion applications and has a density of $1.37 \mathrm{~g} / \mathrm{cm}^{3}$. VA samples were taken from Guneydag tuff ring, which is located $13 \mathrm{~km}$ southwest of Nevsehir, Turkey. Guneydag tuff ring ash samples comprise only volcanic glass. According to the energy dispersive spectrometer analysis, the glass was determined to be the rhyolite (silica rich composition). Major element analysis from all samples gave the same results, indicating the rhyolitic composition of the samples. Nearly 
all vitric grains are angular and highly vesicular. Density and porosity parameters, determined by helium pycnometer and mercury porosimeter, are $1.8-2.4 \mathrm{~g} / \mathrm{cm}^{3}$ and $36-55 \%$, respectively. PVC/VA composite materials were prepared by melt compounding and injection molding processes. For melt compounding, the DSM Xplore $15 \mathrm{ml}$ micro-compounder with a maximum processing temperature of $400{ }^{\circ} \mathrm{C}$ and a screw speed of $250 \mathrm{rpm}$ was used. It has co-rotating twin screw, and its processing temperature can be controlled with six heating zones. DSM Xplore $12 \mathrm{ml}$ injection molding machine was used for injection molding of compounded melt. Maximum processing and mold temperatures are 400 and $200{ }^{\circ} \mathrm{C}$, respectively. Maximum pressure capacity of the machine is 16 bar. All samples were extruded at $195^{\circ} \mathrm{C}$ of mixing temperature and $40 \mathrm{rpm}$ of screw speed and then injected in to the mold at $50{ }^{\circ} \mathrm{C}$, with the injection pressure of 10 bar.

\subsection{Mechanical properties}

The tensile and flexural tests for PVC composite samples with different concentrations of VA were carried out using a Shimadzu AG-X test machine, having a load cell of $10 \mathrm{kN}$, according to ASTM D-638 and D-790 respectively. Tensile and flexural tests were performed at three different temperatures $\left(-10{ }^{\circ} \mathrm{C}, 20{ }^{\circ} \mathrm{C}\right.$ and $\left.50{ }^{\circ} \mathrm{C}\right)$ in a thermostatic chamber with a temperature range between $-30{ }^{\circ} \mathrm{C}$ to $300{ }^{\circ} \mathrm{C}$. Three samples of each category were tested and their average values are reported.

\subsection{Scanning electron microscopy (SEM)}

To characterize the morphology of fractured surfaces and the VA particle dispersion in PVC composites, the surfaces of mechanically tested samples were examined by a SEM (Vega3 SB Easy Probe).

\section{Results and discussion}

The effects of particle concentration of VA on the flexural properties of PVC composites are depicted in Fig. 1.
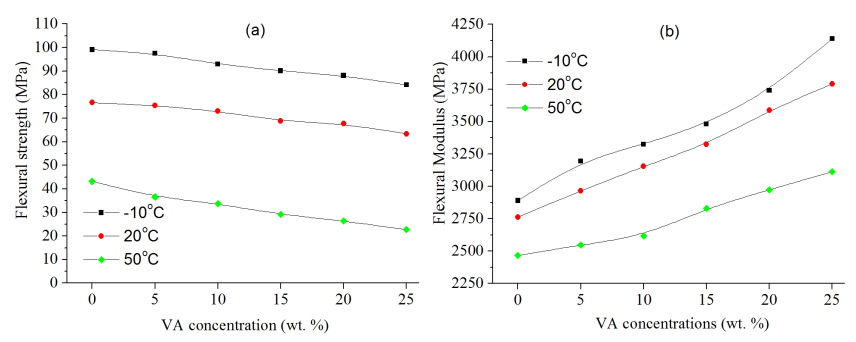

Fig. 1. Flexural test results under different temperatures (a) flexural strength vs VA concentrations (wt.\%),

(b) flexural modulus vs VA concentrations (wt.\%).

The flexural strength $(\sigma)$ values were obtained from the 3PBT (three-Point Bending Test), in MPa, based on the following formula $[9,10]$ :

$$
\sigma=\frac{3 P L}{2 w b^{2}}
$$

where $P$ is the maximum load exerted on the specimen
$(\mathrm{N}), L$ is the distance between the supports $(64 \mathrm{~mm}), w$ is the width $(10 \mathrm{~mm})$ and $b$ is the height of the specimen (4 mm). Flexural modulus can be calculated by using the mathematical equation,

$$
F=\frac{m L^{3}}{4 w b^{2}},
$$

where $F$ is the flexural modulus and $m$ is the slope of the load deflection curve [11]. The incorporation of any concentration of VA into the composites decreased the flexural strength (Fig. 1a). The relatively low flexural strength of VA-filled PVC composites, compared to that of pure $\mathrm{PVC}$ is due to the lower aspect ratio of $\mathrm{VA}$, which resulted in poor interaction between the VA particles and the PVC matrix. Figure 1 also shows that the flexural strengths of PVC/VA composites are decreased with the increase of the VA concentration. This result indicates the tendency of VA particles to agglomerate in PVC matrix at higher VA concentrations. In addition, the effect of VA concentration on flexural strength of PVC composites is similar at all temperatures. At $50{ }^{\circ} \mathrm{C}$, the value of flexural strength of PVC/VA composites with $25 \mathrm{wt} . \%$ of VA is decreased by nearly a half with respect to pure $\mathrm{PVC}$ (Fig. 1a). At $-10^{\circ} \mathrm{C}$ and $20^{\circ} \mathrm{C}$, flexural strength value of PVC/VA composite with 25 wt. $\%$ of VA is decreased by only $15 \%$, with respect to that of pure PVC (Fig. 1a). It can be said, that up to room temperature, $20{ }^{\circ} \mathrm{C}$, even though VA particles decrease the flexural strength of PVC, VA can be used as a filler material in PVC matrix. Figure 1b shows that the incorporation of VA has improved the flexural modulus of the PVC composites. The flexural modulus of the PVC/VA composites were significantly higher than those of PVC matrix at all temperatures. It can be concluded that VA has the ability to stiffen the rigid PVC. It is clearly determined that up to $20{ }^{\circ} \mathrm{C}$, the flexural modulus values have increased by approximately $40 \%$ for concentration of 25 wt. $\%$ of $\mathrm{VA}$, with respect to pure PVC. At $50{ }^{\circ} \mathrm{C}$, the flexural modulus values also increase with the VA concentration, but the increment of flexural modulus values is nearly $25 \%$.

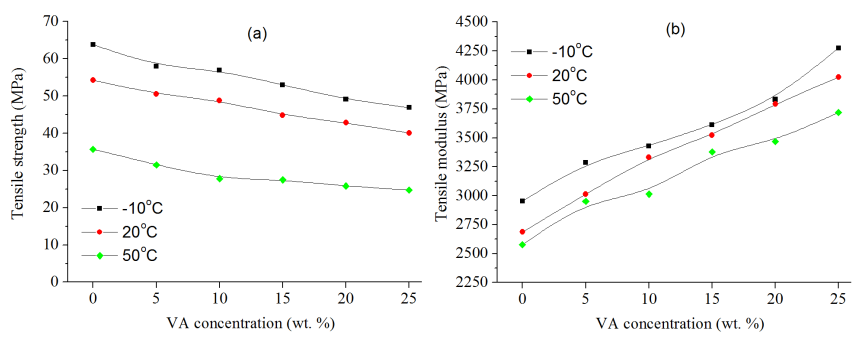

Fig. 2. Tensile test results under different temperatures (a) tensile strength vs VA concentration (wt.\%), (b) tensile modulus vs VA concentration (wt.\%).

Figure 2 illustrates the tensile properties of PVC composites filled with different concentrations of VA. The tensile strength of the composites is decreased gradually upon increasing the VA content, which is similar to results from Ref. 2. The tensile strength of pure PVC is higher than those of the PVC/VA composites at all temperatures (Fig. 2a). Sun et al. [12] reported that the 
tensile strength of composites is influenced by the filler fraction and the interfacial adhesion between the particles and the matrix. The interfacial adhesion plays a crucial role in improving the tensile strength of the composites. The weak interfacial adhesion between the PVC matrix and the filler reduces a large amount of the stress that could be transferred from the matrix to the filler particles [2]. The decrease of tensile strength from 76.5 $\mathrm{MPa}$ down to $64 \mathrm{MPa}$, from $98.3 \mathrm{MPa}$ down to $85.7 \mathrm{MPa}$ and from 43.6 $\mathrm{MPa}$ down to 25.3 $\mathrm{MPa}$, when VA concentration increases up to 25 wt. $\%$, reaches about $15 \%, 13 \%$ and $42 \%$ at $20{ }^{\circ} \mathrm{C},-10{ }^{\circ} \mathrm{C}$ and $50{ }^{\circ} \mathrm{C}$, respectively (Fig. 2a). Besides this, maximum tensile strength values are found at $50{ }^{\circ} \mathrm{C}$. According to the results of flexural properties of PVC/VA composites, at any temperature, the flexural strength values decrease, in a similar way. Figure $2 \mathrm{~b}$ shows the effects of different VA content on the tensile modulus of PVC/VA composites. From Fig. 2b, the tensile modulus of PVC/VA composites with up to $25 \mathrm{wt} . \%$ of $\mathrm{VA}$ is found to increase in average by $49 \%, 36 \%$ and $25 \%$ at $20{ }^{\circ} \mathrm{C},-10{ }^{\circ} \mathrm{C}$ and $50{ }^{\circ} \mathrm{C}$, respectively, compared to pure PVC (Fig. 2b). The increase in stiffness could be attributed to the dispersion of the VA particles, which may also immobilize polymer phases, leading to increased stiffness, in accordance with [13].
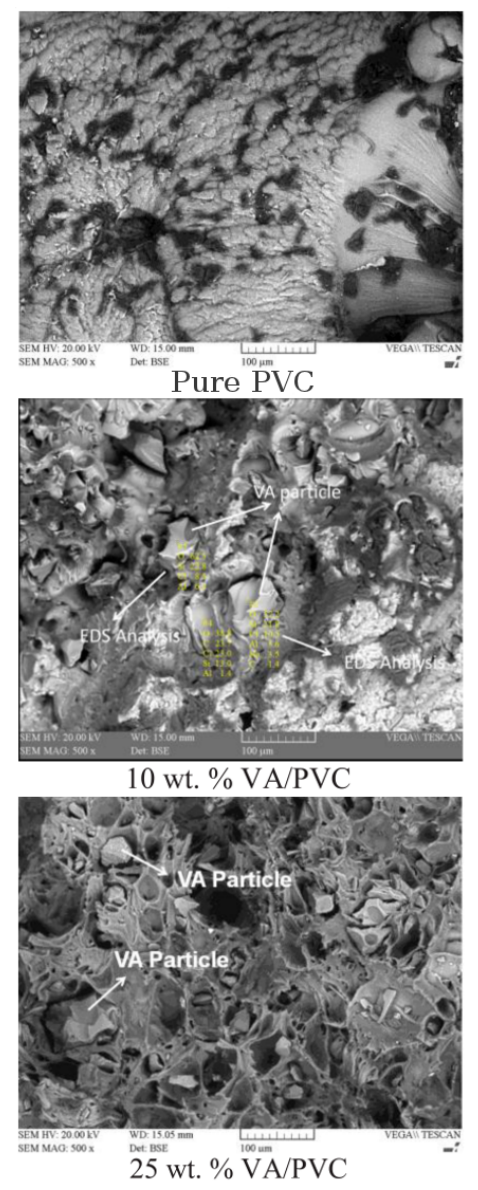

Fig. 3. The morphology of fractured surfaces after tensile tests and the VA particle dispersion in PVC composites at $20{ }^{\circ} \mathrm{C}$ (magnification $500 \times$ ).
The relatively low tensile strength of VA-filled PVC composites, compared to that of the pure PVC, is due to the lower aspect ratio of $\mathrm{VA}$, which resulted in poor interaction between the VA fillers and the PVC matrix. The formation of cavities and fractured surfaces after the tensile tests are shown in Fig. 3. Figure 3 also shows very few broken VA particles on composites surfaces. This finding signifies that the VA filler-matrix interaction is relatively weak, thus allowing debonding to take place before the fully developed plastic deformation and, therefore, causing cavities to form in the composites. In addition, VA particles were studied with EDS analysis (Fig. 3).

\section{Conclusions}

In this study, the influence of concentration of VA particles in the PVC matrix on the tensile and flexural properties was investigated at three different temperatures $\left(-10{ }^{\circ} \mathrm{C}, 20{ }^{\circ} \mathrm{C}\right.$ and $\left.50{ }^{\circ} \mathrm{C}\right)$. The results obtained from PVC composites with different VA concentrations were correlated with the function of flexural strength-modulus and tensile strength-modulus. The results showed that both tensile and flexural strengths decreased with the increasing VA particle concentration. It was clearly observed from SEM images, that filler-matrix interaction was relatively weak, thus allowing debonding to take place before the fully developed plastic deformation and, therefore, causing cavities to form in the composites.

\section{References}

[1] M. Abu-Abdeen, Mater. Design 33, 523 (2012).

[2] B.S. Tuen, A. Hassan, A.A. Bakar, J. Vinyl Addit. Techn. 18, 76 (2012).

[3] E. Avcu, O. Çoban, M.Ö. Bora, S. Fidan, T. Sinmazçelik, O. Ersoy, Polym. Composites 35(9), 1826 (2014).

[4] G. Chen, M. Tian, S. Guo, J. Macromol. Sci. Phys. 45, 709 (2006).

[5] G. Albayrak, I. Aydin, J. Macromol. Sci. Phys. 47, 260 (2008).

[6] F. Gong, M. Feng, C. Zhao, S. Zhang, M. Yang, Polym. Degrad. Stab. 84, 289 (2004).

[7] C. Wan, X. Qiao, Y. Zhang, Y. Zhang, Polym. Test. 22, 453 (2003).

[8] K.M. Asif, M.I. Sarwar, S. Rafig, Z. Ahmad, Polym. Bull. 40, 583 (1998).

[9] M. Moniruzzaman, F. Du, N. Romero, K.I. Winey, Polymer 47, 293 (2006).

[10] F. Mujika, Polym. Test. 25, 214 (2006).

[11] P.N.B. Reis, J.A.M. Ferreira, F.V. Antunes, J.D.M. Costa, Compos. Part A-Appl. S. 38, 1612 (2007).

[12] S.S. Sun, C.Z. Li, L. Zhang, H.L. Du, J.S.B. BurnellGray, Polym. Int. 55, 158 (2006).

[13] M. Mondragon, S.S. Valdes, M.E.S. Espindola, J.E.R. Lopez, Polym. Eng. Sci. 51, 641 (2011). 